\title{
PLANEJAMENTO E GESTÃO ESPACIAL DA POBREZA
}

\author{
ANANYA ROY
}

1 Texto escrito para palestra proferida no ENANPUR 2009. Tradução de Alicia Duarte Penna.
O início deste século foi marcado por uma extraordinária conscientização global sobre temas como a mudança climática e a pobreza. Em minha obra, denomino esse conjunto de ideias e de práticas "desenvolvimento milenário" (millenial development). Desde a ratificação das Metas de Desenvolvimento do Milênio, as grandiosas campanhas globais contra a pobreza, a reformulação do Banco Mundial sob Wolfensohn, até os movimentos sociais globais, o que o desenvolvimento milenário busca é refrear aquilo que Joseph Stiglitz (1999) considerou criticamente como o "fundamentalismo de mercado" da era passada.

O desenvolvimento milenário apresenta desafios excepcionais ao campo disciplinar e profissional do planejamento e dos estudos urbanos. Enquanto diversos temas e setores - no âmbito da pobreza: saúde, empoderamento associado ao gênero, educação, geração de renda e direitos humanos; no âmbito da mudança climática: energia renovável e biocombustíveis - são superestimados no desenvolvimento milenário, pouca atenção é dispensada às cidades. Os principais interlocutores do desenvolvimento milenário estão apenas tangencialmente informados sobre questôes relativas ao planejamento urbano. Por exemplo, a única dentre as Metas de Desenvolvimento do Milênio que possui algum conteúdo urbano é a Meta 7. Essa meta, imprecisamente formulada, baseia-se no que David Satterwaite (2003) denominou "estatísticas non sense". Ainda assim, pode-se argumentar que a condição urbana, que será a condição humana dominante no século 21 , é central a todas as metas de desenvolvimento do milênio. Como os urbanistas, os planejadores e os arquitetos irão se posicionar frente ao desafio de uma pobreza que é persistente? Como a sua compreensão das questões urbanas poderá se tornar relevante, ou mesmo central, ao desenvolvimento milenário? Mas o desafio é ainda mais crucial do que isso: irão as formas do planejamento urbano aprofundar, em vez de mitigar, a pobreza e a desigualdade?

O papel do planejamento na produção da pobreza é particularmente evidente na Índia. A Índia, assim como a China, vem sendo anunciada como uma nova superpotência econômica mundial. Mas essa imagem de uma "Índia dourada" (India shinning) merece um exame mais acurado. Se a Comissão de Planejamento da Índia aponta uma queda abrupta nos índices de pobreza na última década, é preciso levar em conta que a linha de pobreza indiana é, na verdade, uma linha de inanição - 40 centavos de dólar por dia. Quando o limite internacional de pobreza (2 dólares por dia), ajustado segundo a paridade do poder aquisitivo, é aplicado à Índia, cerca de 70\% da população indiana, isto é, 800 milhões, e não 300 milhões de pessoas, são reconhecidas como pobres. A maior democracia do mundo é, de fato, o que um estudioso indiano chamou de "República da Fome" (Patinaik, 2007).

A pobreza na Índia tem raízes em um setor agrícola devastado, mas também são importantes suas manifestações urbanas, sob a forma da migração rural-urbana, das ocupações informais, das favelas, do trabalho informal e temporário, da frágil sobrevivência. Particularmente surpreendente na Índia de hoje é a criminalização da pobreza por parte 
2 Nota do editor. De acordo com a autora, "world-class cities" seriam "cities that conform to global norms of economic competitiveness, urban design, and elite lifestyles", isto é, "cidades em conformidade com as regras da competitividade econômica, desenho urbano e modos de vida da elite". de diversos governos municipais. Enquanto países latino-americanos como o Brasil avançaram em direção a uma compreensão abrangente do "direito à cidade", em uma busca pela democratização tanto da participação no planejamento quanto da própria noção de propriedade, as cidades indianas tornaram-se perversas, repelindo brutalmente a pobreza rural-urbana. Esses são processos de acumulação primitiva, um deslocamento e um fechamento que asseguram, na Índia, os esforços de criar cidades de excelência mundial (worldclass cities). ${ }^{2}$

Esse tipo de urbanismo não pode ser tomado como uma estratégia de globalização ou de ajuste estrutural imposta pelo Ocidente ao resto do mundo. No caso da Índia, eu diria, trata-se de um neoliberalismo endógeno, voltado à produção de cidades de excelência mundial. Arquitetura, desenho urbano e planejamento são elementos cruciais no engenho dessa globalidade. $\mathrm{O}$ que há de fascinante nesses circuitos de produção urbana é que eles tomam como modelo não as cidades ocidentais, mas, em um processo de autoreferência, imagens ideais como Cingapura, Shangai ou Dubai. Trata-se de uma circulação Sul-Sul de ideias e modelos de planejamento, cujas consequências são, contudo, desastrosas para a pobreza urbana. Tais tendências requerem que dediquemos uma atenção redobrada ao papel do planejamento urbano na produção e gestão da pobreza.

\section{OS ESPAÇOS DA POBREZA}

A consolidação da pobreza é uma tendência global. Sabemos que, a despeito dos decréscimos gerais nos índices de pobreza, em muitos países, os números absolutos de pobres têm se mantido, se não aumentado. Sabemos que a desigualdade tem se agravado tanto internamente aos países quanto entre eles. Sabemos também que os perfis estatísti$\cos$ da pobreza não mostram o que seria um conjunto de mudanças estruturais radicais tanto nas naçóes industrializadas quanto naquelas em desenvolvimento. Na realidade, é provável que as atuais e simultâneas crises de alimentos e financeira aumentem o número de pobres em milhões ainda neste ano.

No norte global, no contexto do que Robert Reich (2007) denominou "supercapitalismo", ocorre o que muitos têm chamado de "marginalidade pós-industrial" - a consolidação de formas severas de desemprego e desproletarização, associadas ao retraimento do estado do bem-estar social. No sul global, verifica-se o que Janice Perlman (2004), em seu estudo sobre o Rio de Janeiro, denominou "a realidade da marginalidade". Trata-se, então, de economias desarticuladas, marcadas pela difusão do trabalho informal e por uma persistente vulnerabilidade. Para os planejadores, são significativos os aspectos espaciais dessa pobreza consolidada. Em seu último relatório (2009), o Chronic Poverty Research Centre, com base na Inglaterra, aponta a "desvantagem espacial" como uma das dimensões-chave da pobreza extrema e crônica. Em uma interpretação mais acadêmica, Loic Wacquant (2007) chama atenção para a "estigmatização territorial" como uma clara feição da marginalidade pós-industrial.

Contudo, as geografias da pobreza são mais complexas do que isso. Atentemos para os seguintes aspectos desconcertantes. Enquanto Wacquant e outros têm focado a estigmatização territorial como uma marca da pobreza na América contemporânea, tendências recentes apontam para o que vem sendo nomeado "nova pobreza suburbana", uma geografia mais dispersa do que aquela caracterizada pelo ícone do gueto isolado. No sul global, é algo bastante distinto o que nos desconcerta. Favelas e ocupaçóes informais, ao 
contrário do que Mike Davis (2006) poderia nos fazer acreditar, não são novidade; elas precedem a era do ajuste estrutural e da liberalização. A questão desconcertante é a seguinte: por que, na era passada, tais configuraçôes espaciais eram lugares do emprego, do acesso, da mobilidade, e por que são, agora, geografias da exclusão e da marginalização? Em síntese, para usar as palavras de Susan Eckstein (1990), por que as favelas da esperança tornaram-se favelas do desespero?

Neste ensaio, examino a relação entre planejamento e pobreza, com o objetivo de colocar esta questão: o planejamento é relevante para os desafios colocados neste novo milênio? Gostaria, em particular, de discutir como o planejamento empreende a gestão espacial da pobreza e o quanto essa abordagem é apropriada. Mas se o objetivo é explorar o tema planejamento e pobreza, é preciso examinar também como o planejamento produz a pobreza. Não se trata meramente de como o planejamento pode mitigar a pobreza. Ao contrário, trata-se de como o planejamento está implicado na produção da pobreza. É indefensável, creio eu, caracterizar a pobreza simplesmente como uma questão de negligência do Estado. Em vez disso, a pobreza e as geografias da pobreza devem também ser compreendidas como efeitos do Estado, na medida em que envolvem tanto a exclusão territorial quanto a estigmatização territorial. Assim, no contexto dos Estados Unidos, se pensamos sobre a estigmatização territorial que está associada ao gueto como espaço fechado e isolado, então precisamos pensar sobre um espaço que está inextricavelmente ligado ao gueto: o intocável subúrbio. Nesse contexto, muitas décadas de políticas públicas criaram um enclave apartado, distintivo, seguro, e fechado. Na história da expansão metropolitana nos Estados Unidos do século 20, guetização e suburbanização são dois lados de uma mesma moeda. A verdadeira política habitacional dos Estados Unidos não foi a construção de enclaves para os pobres, e sim o contrário, sólidos subsídios para a classe média proprietária, mediante deduções de impostos em suas hipotecas. Isso é planejamento urbano nos Estados Unidos. Isso é produção de vantagem espacial. Isso é desenvolvimento territorial.

O planejamento também produz desvantagem espacial. Se desejamos, de fato, avançar nessa questão, creio ser crucial compreendermos a difícil história do papel do planejamento na produção da vantagem e da desvantagem espaciais. Exemplos cabais, nesse âmbito, são as cidades coloniais francesas no norte da África. Embora seja possível descartar o urbanismo colonial como uma forma anômala de planejamento, seria um erro fazêlo. A arquitetura e o urbanismo modernos, como observaram Paul Rabinow, Gwendolyn Wright e muitos outros, foram refinados no excruciante colonialismo do século 19 (vejase AlSayad, 1992). Efetivamente, as colônias foram fronteiras de experimentação de planejamento e de projeto, uma extensão da haussmanização posterior ao encerramento dessa era na Europa.

Assim foi quando Le Corbusier chegou a Argel em 1930, durante as comemorações do centenário da ocupação francesa na Argélia. Em sua concepção, o colonialismo é retratado como um eixo de ideias, partindo de Argel, e daí se estendendo mais longe ao sul, em direção à África francesa. Esse era, evidentemente, o eixo ao longo do qual se estava instalando uma distinta troca colonial - de acumulação primitiva e modernização sangrenta. Corbusier proclamou a cidade de Argel como "a mais bela do mundo", uma cidade branca debruçada sobre o mar. Mas como esse espaço urbano poderia ser planejado e gerido? O Plano Obus de Le Corbusier pretendia preservar intacta a casbá: sobre ela, uma via expressa flutuante ligaria as expansões planejadas da zona residencial europeia à zona de negócios europeia. Os viadutos serviriam como habitação para os trabalhadores arge- 
linos, uma pungente imagem da infraestrutura colonial, uma cidade literalmente construída nas costas dos trabalhadores nativos. Representada tal como uma mulher reclusa, a casbá permaneceria em quarentena, detrás de um cordon sanitaire vertical. Eis aqui a potencialidade de uma estigmatização territorial cujo legado tem sido difícil apagar - a divisão colonial entre a cidade branca e a nativa, entre a mobilidade espacial e a segregação espacial. Ironicamente, foi mediante a demarcação da casbá como um espaço protegido e controlado que o estado francês colonial tornou-se capaz de articular sua missão de administrar aquele território. Assim, o plano de Corbusier apresentou as razōes de uma "regra da diferenciação", segundo a qual o mundo europeu e o muçulmano, sendo essencialmente diferentes, assim deveriam permanecer. Cabe lembrar que esse mesmo plano tem sido celebrado como um ícone do planejamento modernista. Manfredo Tafuri (1979) descreve o Plano Obus como a "mais elevada hipótese teórica do urbanismo moderno... o repositório de uma nova escala de valores... uma estratégia de integração coletiva”.

Uma observação: conquanto o Plano Obus jamais tenha sido implantado, as formas de segregação espacial, previstas por Corbusier, já eram uma peça-chave no planejamento colonial francês. Não obstante, seria nesses guetos de nativos que a grande luta pela independência da Argélia (Lamprakos, 1992) teria início. O aparato militar do regime colonial mostrou-se incapaz de penetrar, compreender e controlar o próprio espaço que ele criara, história magistralmente contada no filme de Gillo Pontecorvo, Battle of Algiers.

\section{A GESTÃO ESPACIAL DA POBREZA}

Ao narrar essas histórias no contexto contemporâneo do planejamento e da pobreza, pretendo indicar os complexos legados da exclusão e da estigmatização territorial com que devemos nos confrontar. Desejo iluminar, em especial, aquilo que caracteriza as intervenções do século 20: a gestão espacial da pobreza. Detenhamo-nos agora, ainda que brevemente, em dois paradigmas comuns da gestão espacial da pobreza e em como eles permanecem inadequados como modelos de planejamento.

O primeiro é mais conhecido por seu nome um tanto burocrático: urbanização de favelas. Popular na década de setenta do século 20 , sob a forma de programas assistenciais locais, a urbanização de favelas retorna na década de 1990. Embora associada à ideia, mais ambiciosa, de regularização fundiária, é a urbanização de favelas, mais do que a própria regularização fundiária, que tem sido a via mais comum da gestão da pobreza. A urbanização de favelas é uma alternativa ao mesmo tempo humana e pragmática para a devastação e a expulsão resultantes de demoliçōes e remoções. Há, porém, inegáveis limitações à urbanização de favelas. Tais limitaçôes estão evidentes nos debates em curso sobre o Programa Favela-Bairro, os quais são familiares aos arquitetos e urbanistas brasileiros.

No sul da Ásia há um programa semelhante e bem conhecido: o Slum Networking Project, em Indore, na Índia. Idealizado pela British Aid Agency, DFID, e implementado pela Indore Development Authority, esse projeto objetiva integrar as favelas ao sistema de saneamento da cidade. Uma ideia-chave do programa é assegurar que cada família na favela seja servida por um banheiro próprio, por sua vez ligado ao sistema de esgotamento sanitário da cidade. Vencedor de prestigiosas premiaçóes internacionais, do Prêmio Aga Kahn ao Habitat, o programa, na realidade, foi um desastre. Em uma crítica mordaz, Gita Dewan Verma (2000), uma das consultoras sênior do projeto, revela o quanto famílias pobres são incapazes de pagar por banheiros individuais, e o quanto relutam em fazê-lo - 
elas não dispõem nem do espaço nem dos recursos necessários a tais instalações. Não obstante, os engenheiros não só haviam presumido que todos os moradores das favelas priorizariam mais do que qualquer coisa aqueles banheiros, como planejado um sistema de saneamento cuja ligação seria completa. Sem essa ligação completa, as redes se obstruíram rapidamente, deixando as favelas literalmente imersas na lama.

Esses projetos, bem-intencionados mas desastrosos, requerem um exame cuidadoso, por revelarem pressuposiçōes e ideologias presentes na gestão espacial da pobreza. A mais importante dentre elas é a que denomino "ideologia do espaço". A urbanização de favelas objetiva melhorar e valorizar o espaço físico, mas raramente conduz à valorização dos modos de vida, à valorização do poder político, à valorização das redes sociais. O paralelo com a gentrificação é óbvio. Assim, não é surpreendente que projetos de urbanização de favelas dêem início a processos de gentrificação. Em muitos casos, as famílias pobres são expulsas, incapazes de arcar com a regularização imposta pelo processo. $\mathrm{Na}$ verdade, ao tomar o espaço simplesmente como um objeto a ser melhorado, a urbanização de favelas ignora os aspectos temporais da pobreza, esquece que, na realidade, os serviços disponibilizados dificilmente podem ser sustentados pelos pobres urbanos, pois há uma incompatibilidade entre a sistemática irregularidade do seu emprego e a regularidade institucionalizada dos pagamentos que passam a dever na favela urbanizada.

A urbanização de favelas, portanto, pode se tornar uma estranha combinação de estigmatização territorial e nostalgia. Ela é caracterizada pela imaginação da "favela", um espaço de uma exótica diferença - tão absoluta quanto a casbá em quarentena de Corbusier - e, ainda assim, nas práticas de urbanização de favelas de planejadores e arquitetos, um espaço que pode se tornar lindo, um espaço que arquitetos e planejadores frequentemente imaginam como uma atemporal "aldeia comunitária". Esses planejadores e arquitetos são então surpreendidos quando, entre os pobres, agentes buscam resistir a esses ambientes qualificados. Afinal, isso resulta, como Ismail Serageldin (1997) definiu, numa nova "arquitetura do empoderamento" - essa em que, mediante as melhorias físico-territoriais, os pobres são largados ao seu próprio destino. Em minha obra, venho chamando essa abordagem de esteticização da pobreza.

A ideologia do espaço tem uma longa história no planejamento e na arquitetura ela fala ao determinismo ambiental, do qual esses profissionais parecem não poder se livrar; ela fala à combinação entre ordem visual e ordem funcional. Trata-se também de uma romantização, tal como a celebrada concepção de Hernando de Soto [2000], que vê os pobres como empresários heróicos, e o seu urbanismo informal como um exemplo de revolução popular. Cabe perguntar, porém, se melhorias físico-territoriais podem mudar o destino das favelas do Rio e dos slums da Índia, ou se não passam, como um crítico observou, de um rearranjo de espreguiçadeiras enquanto o Titanic afunda (Auyero, 1999).

É provável que o maior desafio colocado pela urbanização de favelas, em relação à gestão espacial da pobreza, seja a realidade do urbanismo, aquela que um filósofo francês, Henri Lefebvre (1974), designou como "a produção do espaço" - fronteira de desenvolvimento, onde o espaço é, de fato, mercadoria preciosa e circuito vital da acumulação de capital. Não é de se surpreender então que a urbanização de favelas tenha sido substituída pelo que atualmente está sendo chamado de reassentamento conduzido pela comunidade. Por exemplo, em Mumbai, o Banco Mundial conta com organizaçóes da sociedade civil, tais como a SPARC - Society for the Promotion of Area Resource Centers, para abrir espaço para a extensão de ferrovias e vias expressas. Milhares de moradores de ocupaçôes informais e favelas demoliram, voluntariamente, suas próprias casas, e se muda- 
ram para assentamentos negociados pela SPARC. Isso, para a SPARC, é "fazer as pazes" com a cidade, já que os pobres não têm outra opção que não seja dar lugar ao desenvolvimento. Desse modo, a ideologia do espaço torna-se uma estratégia de produzir o espaço para um urbanismo de elite, para a cidade de excelência mundial que não pode admitir a desordem visual. O planejamento fará as pazes com essa cidade de excelência mundial, e mesmo a favorecerá? Ou buscará confrontar e transformar a produção do espaço? Muitos dos que trabalhamos nessas partes do mundo olhamos com grande esperança para o Brasil, pois é aqui que a produção mesma do espaço está sendo confrontada pelo aparato do planejamento.

Um segundo paradigma do controle espacial da pobreza é o populismo urbano. Tomei esse termo emprestado do livro seminal de Manuel Castells [1983], The city and the Grassroots. Numa análise influente, Castells designa as políticas de provimento de serviços aos assentamentos urbanos periféricos como populismo urbano, como cooptação dos pobres pelo aparelho político do clientelismo. Isso também é gestão espacial da pobreza, pois se trata de prestar serviços e apoio a uma particular comunidade ou formação socioespacial.

Essas formas de populismo - evidentes nos serviços provisionados pelas milícias urbanas, tal como o Hezbolá, no Líbano - atravessam o espectro político. Sem dúvida, nos subúrbios ao sul de Beirute, na região conhecida como gueto xiita, ou Al-Dahiya, o Hezbolá é o Estado de facto, provendo água, escolas, refeitórios, e mesmo controlando os processos de planejamento urbano e de reconstrução pós-guerra.

A Venezuela de Chávez, um dos mais controversos contextos de desenvolvimento do mundo, é um exemplo desse populismo? Desde que chegou ao poder, Chávez está empenhado em usar os recursos gerados pelo petróleo venezuelano para mitigar a pobreza, projeto que ele próprio intitulou "socialismo do petróleo". Em comunhão com as ideias de Simon Bolívar, seu governo vem estabelecendo missões bolivarianas, iniciativas anti-pobreza que incluem escolas, clínicas cujo corpo de funcionários é composto por médicos cubanos, e postos de abastecimento em que os alimentos são subsidiados. Os gastos públicos em setores-chave do desenvolvimento social aumentaram, e a pobreza parece ter se retraído. Mas, quando os preços do petróleo caem, como ocorreu recentemente, o petrosocialismo é capaz de se sustentar? E o que fazer com os subsídios para os ricos, que também fazem parte desse mesmo petro-socialismo, cujos incríveis subsídios concedidos aos combustíveis beneficiam não os pobres que dependem de transporte público, mas especialmente os proprietários de automóveis? A Venezuela continua a ser um dos países mais desiguais do mundo, a despeito da suposta revolução bolivariana. Em uma dissertação em curso na University of Califórnia, Berkeley, Carmen Rojas analisa esse "urbanismo revolucionário", descobrindo sua hostilidade com alguns segmentos da pobreza urbana. Ela registra as constantes expulsões dos camelôs, acusados pelos planejadores de Caracas de e esse é um ponto sensível para mim, pois nasci em Calcutá - "ter transformado Caracas em Calcutá". Para mim, a Venezuela de Chávez é um exemplo de "petro-populismo", um instrumento de clientelismo seletivo patrocinado pelo Fundo para o Desenvolvimento Nacional, um fundo de 14 bilhóes de dólares despendido segundo a vontade soberana de Chávez. Em um ensaio escrito há alguns anos, em parceria com Nezar Al Sayyad, intitulado "Modernidade Medieval", argumento que essas várias formas de populismo, que deveriam servir aos pobres, criam uma geografia fractal de enclaves, de sistemas privados de governança e para-Estados que operam como senhores feudais medievos. Sob o populismo, a cidadania deve ser compreendida como algo condicional, parcial e situacional, pois 
os pobres são incluídos, mas no sentido mais dramaticamente reduzido de clientelismo. $\mathrm{Na}$ verdade, esses tipos de medievalismo questionam o próprio ideal moderno de cidade, de civitas.

O que pode ser feito então? Voltemos aos programas anti-pobreza que não empreendem o controle espacial da pobreza - em outras palavras, que não buscam mitigar a pobreza localizada em uma comunidade ou região demarcada, e nem se valem dos instrumentos do determinismo ambiental. Eles são, creio eu, bastante promissores.

\section{O ENFRENTAMENTO DO “SOCIAL"}

Um das mais importantes ações no âmbito da pobreza é o movimento pelo "direito à cidade" no Brasil, formalizado no Estatuto da Cidade. O Estatuto objetiva democratizar o acesso a terra e a habitação nas cidades brasileiras, bem como democratizar o processo de gestão urbana. Ele inclui a afirmação de direitos coletivos, inclusive o direito ao planejamento urbano, o direito à captação da mais-valia, e o direito à regularização de assentamentos informais. Trata-se, como Edésio Fernandes (2007) observou, de um novo "projeto de cidade", tradução, em termos espaciais, do "projeto social" proposto por Henri Lefebvre.

O modelo brasileiro é também inovador em relação a outras ações empreendidas na América Latina. Por exemplo, Bogotá tem sido aclamada mundialmente como um modelo de democratização do espaço urbano. Chamo essa espécie de planejamento urbano de "urbanismo pedagógico", já que são exemplos de ações de planejamento implementadas por prefeitos carismáticos, tais como Peñalosa, na intenção de criar uma pedagogia da cidade - o respeito ao pedestre, a valorização do espaço público, a restrição ao automóvel. Trata-se de um modelo importante que traz semelhanças interessantes com experimentos urbanos no outro lado do mundo como, por exemplo, em Cingapura. Mas o Estatuto da Cidade brasileiro é de uma espécie diferente. Em vez de propor um modo de gerir o espaço, ele busca alterar os próprios modos pelos quais o espaço produz valor e funciona ao mesmo tempo como uma mercadoria e um bem coletivo. Isso é um avanço em relação ao controle espacial da pobreza. No contexto africano, Abdoumaliq Simone (2005) fala sobre o "direito à cidade" como o "direito a múltiplas aspiraçôes". A promessa do Estatuto da Cidade é a de que, mediante o planejamento, tal direito seja reconhecido e institucionalizado. Evidentemente, resta verificar se essa promessa foi, ou não, cumprida.

Há ainda outro tipo de programa anti-pobreza que acredito ser promissor: a proteção social. Esse é um termo que, tendo se tornado amplo, abrange uma amplitude de ações que merecem ser examinadas. Uma delas é a transferência condicional de recursos: pequenos pagamentos feitos às famílias pobres, mas sob condições ante as quais lhes são confiados vários itens de desenvolvimento social, tais como mandar as crianças para a escola, visitar postos de saúde, e assim por diante. Um dos programas de transferência condicional de recursos mais conhecidos é mexicano: o Programa Oportunidades, antes popularizado como Progresa. Focado principalmente nas mulheres, creditam-se a esse programa substanciais decréscimos na pobreza. $\mathrm{O}$ programa persegue metas ao mesmo tempo geográficas e econômicas, visando aos pobres, mas não admite discriminação local alguma, centralizando a alocação da transferência de recursos com a finalidade de desviarse dos sistemas populistas de clientelismo. No contexto brasileiro, um dentre esses pro- 
gramas é o Bolsa Família, ao qual se credita a garantia da reeleição de Lula, no pleito de 2006, pelos votos dos "de baixo".

Os programas de transferência condicional de recursos são alvo de calorosos debates. Alguns críticos vêem-nos como políticas neoliberais que meramente provêm incentivos monetários com a finalidade de transformar a "cultura da pobreza"; outros argumentam que são programas populistas, que mantêm, ou mesmo aprofundam, os sistemas de clientelismo; e outros, ainda, defendem - e essa crítica é muito frequente em relação ao Bolsa Família - que esses programas são realizados à custa do investimento a longo prazo em desenvolvimento, especialmente orientado a setores-chave como educação, habitação e saneamento. Em um artigo na New Left Review, Francisco de Oliveira (2006) declara: "O Bolsa Família serve para despolitizar a questão da pobreza, transformando a desigualdade em problema administrativo, vedando a possibilidade de qualquer projeto de desenvolvimento nacional ou transformação radical das relações sociais". Mas há quem veja esses programas de forma diferente. De Janvry e Sadoulet (2004) argumentam que eles são um experimento social-democrático, devendo ser compreendidos como contratos sociais, com beneficiários, para a distribuição de um serviço. Talvez a interpretação mais interessante da transferência condicional de recursos venha de um antropólogo, James Ferguson (2008), imerso nos debates sul-africanos sobre a introdução da Concessão de Renda Básica. Ele vê esse programa de proteção social como uma "renda cidadâ", em que se reconheceria uma espécie de associação e de solidariedade de toda a nação que transcenderia os rituais políticos (frequentemente vazios), tais como votar, para incluir direitos à sobrevivência e ao consumo.

A proteção social também está no centro das ações sobre a pobreza em Bangladesh. Nos últimos anos, venho pesquisando a configuração de suas instituições e de seus programas. Quase sempre reconhecidas por suas iniciativas de microcrédito, essas instituições de fato fazem algo mais, e algo bem diferente. Seguramente, é uma vergonha que tais instituições sejam conhecidas somente pelo microcrédito. $\mathrm{O}$ microcrédito, acredito, é um tipo de empréstimo de risco, em que a exclusão dos pobres do acesso às instituições financeiras é substituída pela inclusão, mas por uma forma severamente segmentada de inclusão. Em Bangladesh, essas instituições alcançam resultados bem distintos. Hoje, credita-se ao seu trabalho o que tem sido popularmente chamado de "paradoxo de Bangladesh" - o de que este, que é um dentre os países mais pobres do mundo, afligido por desastres naturais e instabilidade política, tenha realizado poderosos avanços em desenvolvimento humano. A história do paradoxo de Bangladesh não é contada nos círculos internacionais do planejamento, mas é hora de fazê-lo. O trabalho de instituições focadas na pobreza é a chave para a compreensão dos avanços em Bangladesh. De fato, essas instituições, dentre as quais o Grameen Bank e a BRAC - Bangladesh Rural Advancement Committee (atualmente Building Resources Across Communities) são as mais conhecidas, atendem a milhōes de famílias, e são possivelmente as maiores instituições anti-pobreza do mundo.

No meu ponto de vista, há três elementos-chave no sucesso dessas instituições e de seus programas para a pobreza em Bangladesh. Primeiro, elas focam em crédito habitacional e serviços para os pobres, uma ênfase que as coloca entre os programas de proteção social à família. É assim que o Grameem torna possível que as mulheres mais pobres do mundo tenham suas próprias casas. Esse modelo não é exclusivo do Grameen Bank. Na Índia, a SEWA - Self-Employed Women's Association, que é o maior sindicato de mulheres do mundo, organiza trabalhadoras do setor informal. Reconhecendo que raramente as mulhe- 
res têm acesso à propriedade da terra, informal ou não, a SEWA concede-lhes financiamento habitacional. Embora grande parte desse financiamento habitacional seja empregado pelas mulheres em reformas e melhoramentos em suas casas, os empréstimos servem a um propósito muito mais amplo. Eles constituem uma oportunidade de afirmar o direito das mulheres à habitação, de insistir em sua participação na propriedade da terra, de reivindicar a segurança do título de posse. E a SEWA faz isso registrando o nome delas nos títulos de propriedade, nas guias dos impostos prediais, nas contas de energia elétrica - em resumo, nos documentos formais e informais que constituem a agenda de reivindicaçóes dos pobres urbanos. Essas ações anti-pobreza não são, portanto, tão atreladas assim às finanças ou ao crédito, mas à negociação da desigualdade social, à mudança das regras do jogo.

Segundo, essas instituiçóes criam uma infraestrutura de desenvolvimento que se estende à maior parte da Bangladesh rural. O último relatório (2009) divulgado pelo Chronic Poverty Research Centre afirma que a infraestrutura, assim como os serviços de transporte e de saúde, são a chave para pôr fim à desvantagem espacial vivida pelos pobres. Em Bangladesh, a BRAC, por exemplo, atende a cerca de 12 milhões de pessoas através de suas organizações comunitárias, clínicas de saúde e escolas primárias, e de projetos de economia popular e solidária, os mais recentes envolvendo setores como laticínios e avicultura. Tais infraestruturas não necessariamente substituem o papel do Estado; ao contrário, eu diria, pressionam o Estado a corresponder àqueles serviços.

Terceiro, e isso pode ser surpreendente: a chave para esses programas anti-pobreza não é o crédito - a despeito de toda a propaganda que o próprio Grameen Bank faz circular sobre o crédito como um direito humano. A chave está em poupar. Essas instituições encorajam, na verdade forçam, os pobres a poupar. Essa poupança permite não somente às instituições, mas também aos pobres, gerir os riscos do financiamento. Trata-se de uma gestão não do espaço, mas do tempo. Se concebemos a pobreza, nas palavras do antropólogo Arjun Appadurai (2001), como a "tirania da emergência", então o valor de uma abordagem como essa fica evidente.

Esses programas de proteção social em Bangladesh não se engajam na gestão espacial da pobreza, mas são, tal como o é o direito à cidade, inevitavelmente espaciais. Por uma razão, ao atacar a pobreza rural, eles pretendem mitigar as desigualdades ruralurbanas e reduzir a torrente de imigrantes desafortunados do campo para a cidade. Em Bangladesh, onde todas as maiores instituições anti-pobreza atuam em áreas rurais, a tendência, sem dúvida chocante, é a de que, enquanto os indicadores de desenvolvimento humano continuam a melhorar nas áreas rurais, eles continuam a piorar nas áreas urbanas.

Penso que o planejador pode extrair liçōes muito importantes desses programas. A primeira, acredito, é a de que o planejamento tem que deslocar seu foco do uso da terra para a propriedade. Esse é o caso do Brasil - e é o movimento acertado -, mas não o que estamos vendo nas outras partes do mundo. Ao focar por tanto tempo o espaço ao qual as coisas pertencem, os planejadores esqueceram-se de perguntar a quem as coisas pertencem. É claro que não há uma resposta simples para isso, pois há múltiplas e controversas respostas à questão: a quem as coisas pertencem? O modelo da propriedade privada insiste no "direito de excluir". Mas, nas cidades pelo mundo afora, o direito de excluir é desafiado por aqueles que reivindicam o direito de não ser excluído.

A segunda, a de que arquitetura e planejamento terão que lidar com uma nova realidade material, aquela da marginalidade avançada, da reestruturação econômica difundida tanto no norte quanto no sul global, a tal ponto que já não é mais possível fundamen- 
Ananya Roy é professora do Department of City and Regional Planning da Universidade da Califórnia, Berkeley. É também diretora de Educação do Blum Center for Developing Economies e co-directora do Global Metropolitan Studies Center. É autora de City Requiem, Calcutta: Gender and the Politics of Poverty e co-editora de Urban Informality: Transnational Perspectives from the Middle East, Latin America, and South Asia. Em breve lançará Poverty Capital: Microfinance and the Frontiers of Millenial Development. E-mail: ananya@berkeley.edu tar as ideias de justiça social na realidade do trabalho. De fato, como Ferguson (2008) observa em relação à África do Sul, a informalização generalizada da economia sugere que a própria noção de "índice de desemprego" é arcaica - "um indicador de meados do século 20 inadequado à economia e à sociedade do século 21 ”. É por essa razão que os programas de proteção social devem ser efetivamente programas anti-pobreza, e não se basearem na ideia de trabalho assalariado.

Finalmente, a de que o planejamento terá que se confrontar com um desenvolvimento associado ao gênero. A alavanca de muitos dos programas anti-pobreza nesse milênio são as mulheres pobres. Antes meras vítimas indefesas, hoje as mulheres pobres do sul global são vistas como salvadoras. Muitos dentre esses programas que descrevi dependem de mulheres pobres. Por exemplo, a chave do sucesso do aclamado programa mexicano de transferência de recursos, Oportunidades, é a incorporação em seus quadros de Organizações de Mães. O programa fundamenta-se na ideia de "co-responsabilidade", fazendo das mães "as principais responsáveis por assegurar os resultados dos programas". A teórica feminista Maxine Molyneux (2006), acertadamente, pergunta se isso não seria um "altruísmo feminino a serviço do Estado". De fato, estamos testemunhando uma "femininização da responsabilidade e do dever", em que as mulheres pobres estão carregando nas costas os pesados fardos do desenvolvimento comunitário, da mitigação da pobreza, e mesmo do que se pode chamar de planejamento (Chant, 2008). Esses fardos aprofundarão a exploração associada ao gênero, ou alterarão as hierarquias de gênero?

Cada um desses temas tem um componente espacial, inevitavelmente. Na verdade, pode-se perguntar o que é o planejamento senão organização do espaço. Além do mais, esses três temas não podem ser abordados mediante técnicas de gestão espacial, como a urbanização de favelas ou a espacialização do clientelismo. Eles requerem novas formas de significação urbana, uma nova compreensão de justiça social, e a confrontação com hierarquias sociais. Tenho a esperança de que o planejamento, nesse novo milênio, será capaz de lidar com essas questóes, superando, assim, o legado do determinismo ambiental.

\section{REFERÊNCIAS BIBLIOGRÁFICAS}

ALSAYYAD, N. (1992) Forms of Dominance: On the Architecture and Urbanism of the Colonial Enterprise. Aldershot: Avebury.

APPADURAI, A. (2001) Deep democracy: urban governmentality and the horizon of politics. Environment and Urbanization, 13:2, pp. 23-44.

AUYERO, J. (1999) This is a Lot Like the Bronx, Isn't It? Lived Experiences of Marginality in an Argentine Slum. International Journal of Urban and Regional Research 23:1, pp. 45-69.

CASTELLS, M. (1983) The City and the Grassroots. Cambridge: Blackwell.

CHANT, S. (2008) The "feminisation of poverty" and the "feminisation" of anti-poverty programmes: room for revision?. Journal of Development Studies, 44(2): pp. 165-197.

Chronic Poverty Research Centre (2008) The Chronic Poverty Report 2008-09: Escaping Poverty Traps, Brooks World Poverty Institute, University of Manchester.

DAVIS, M. (2006) Planet of Slums. New York: Verso.

DE JANVRY, A.; SADOULET, E. (2004) Conditional cash transfer programs: are they really magic bullets?. ARE Update, 7(6): 9-11. Online. Disponível em: http://www.agecon.ucdavis.edu/extension/update/articles/v7n6_3.pdf (acesso em 2 de dezembro de 2008). 
DE SOTO, H. (2000) The Mystery of Capital: Why Capitalism Triumphs in the West and Fails Everywhere Else. New York: Basic Books.

ECKSTEIN, S. (1990) Urbanization Revisited: Inner-City Slums of Hope and Squatter Settlements. World Development 18:2, pp. 165-81.

FERGUSON, J. (2008) Declarations of Dependence: Labor, Personhood, and Welfare in South Africa. Unpublished presentation, UC Berkeley Peripheries Working Group.

FERNANDES, E. (2007) Constructing the Right to the City in Brazil. Social \& Legal Studies 16, pp. 200-219.

LAMPRAKOS, M. (1992) Le Corbusier and Algiers: The Plan Obus as Colonial Urbanism. In: ALSAYYAD, N. (Ed.). Forms of Dominance: On the Architecture and Urbanism of the Colonial Enterprise. Aldershot: Avebury.

LEFEBVRE, H. (1974) The Production of Space (transl. by D.N. Smith, 1991 edition). Cambridge: Wiley Blackwell.

MOLYNEUX, M. (2006) Mothers at the service of the new poverty agenda: Progresa/Oportunidades, Mexico's conditional transfer programme. Social Policy and Administration 40(4): pp. 425-449.

OLIVEIRA, F. (2006) Lula in the Labyrinth. New Left Review 42, pp. 5-22.

PATNAIK, U. (2007) The Republic of Hunger. Delhi: Three Essays Collective.

PERLMAN, J. (2004) Marginality: From Myth to Reality in the Favelas of Rio de Janeiro. In: ROY, A.; ALSAYYAD, N. (Eds.). Urban Informality: Transnational Perspectives from the Middle East, Latin America, and South Asia. Lanham, MD: Lexington Books.

Reich, R. (2007) Supercapitalism: The Transformation of Business, Democracy, and Everyday Life. New York: Knopf.

SATTERTHWAITE, D. (2003) The Millennium Development Goals and Urban Poverty Reduction: Great Expectations and Nonsense Statistics. Environment and Urbanization 15, pp. 179-190.

SERAGELDIN, I. (1997) The Architecture of Empowerment: People, Shelter, and Livable Cities. Lanham: Academy Editions.

SIMONE, A. (2005) The Right to the City. Interventions 7:3, pp. 321-325.

STIGLITZ, J. (1999) The World Bank at the Millennium. The Economic Journal 109: 459, F577-F-597.

TAFURI, M. (1979) Architecture and Utopia. Cambridge: The MIT Press.

VERMA, G. D. (2000) Indore's Habitat Improvement Project: Success or Failure?. Habitat International 24, pp. 91-117.

WACQUANT, L. (2007) Urban Outcasts: A Comparative Sociology of Advanced Marginality. Cambridge, United Kingdom: Polity. 